\title{
Current Approach towards Dissemination of Ideas and Combating Social Taboos in India
}

\author{
Dr. Manavpreet Kaur Arora
}

\begin{abstract}
There is a magnanimous change in attitude towards taboo subjects in India which is evident in the attitude adopted by content creators and users. The core concern of this research is to analyse the change in visual strategies adopted in the current decade towards subjects such as gender bias, menstruation and homosexuality.

This is a qualitative research where data collection encompasses case study of short films uploaded on You Tube since 2010. Analysis of the visual approach is done on the parameter of appeal adopted, selection of cast, broad societal context represented and its overall aesthetics.

The results decipher that more celebrity actors and directors have recently opted for the impudence of short films and a backdrop of a middle class background for maximum reach. The visual approach is a balanced mix of pragmatism and emotions. The count of viewership and outnumbering likes are indicative of change in social attitudes.
\end{abstract}

Keywords: Taboos, Short Films, Gender Bias, Homosexuality, Menstruation

\section{INTRODUCTION}

Taboos in Indian society have existed since centuries and various efforts have been made to eradicate them. Technological innovations meant to reach the masses contribute immensely in creating awareness against their practice and initiating a dialogue to bring about a social change. Commercial advertisements and cinema have long provided avenues for entertainment and a medium for experimentation to subtly bring about a change in the rigid societal notions. However, the current popular format for reaching out to the masses with low budget and more freedom of expression is through short films. The existing plethora of short films resorts to an eclectic mix of ideas and emotions. Of these, a few are dedicated to the cause of various social taboos that exist in India. This trend has been rapidly growing in the current decade and there have been dedicated You Tube channels which adopt tabooed subjects for expressing their creativity and ushering a social change.

You Tube, a trending platform for sharing ideas is widely adopted by the creative community of directors for releasing their short films. The feature of interactivity allows for instant feedback and discussion, encouraging the You Tubers to launch their own channels and experiment further. With its growing popularity, commercially successful celebrities have also endorsed this format, adding to the chutzpah of the narratives and furthering its reach. Since the only information about a film's content is a brief description of the plot, the research aims at critically analysing its content with reference to its approach in eradicating taboos in the Indian society. Various You Tube channels such as Six Sigma Films, Long Short Films, Girliyapa, Pocket Films etc. are supporting the cause of taboos though their creative short films.

\section{MATERIALS AND METHODS}

Many scholars have attempted to define the characterization of women in Indian cinema and advertisements in the context of gender inequality, defining gender roles and objectification. There are very few research articles on representation of homosexuality in films and almost none on the theme of menstruation in films. There is no research on the format of short films in India though there is an abundance of online articles for reviews and trends in the same. The aim of present research is to apply the parameters and understanding of cinematic genres and aesthetics to the medium of short films; which are rapidly growing in popularity and creating an interactive impact on the society.

Subhas Singha Roy (2012) makes an extensive study on portrayal of women in Indian electronic media. The paper primarily deals with channels programs and advertisements which categorically showcase women in traditional roles. However, the paper does not look at the format of films and short films. Martino Cipriani published an online paper on the notion of gender and sexuality in Indian Films which was a case study based on representation of women in three successful Bollywood movies i.e. Mother India, Sholay and Dilwale Dulhaniya Le Jaenge.

Ruchi Aggarwal (2014) in her research article on Changing Roles of Women in Indian Cinema critically traces the evolution of representation of women in the defined gender roles and her objectification. Shyama Kumari and Shradha Shivani (2015) have done an extensive research on portrayal of women in contemporary Indian advertisements and their stereotypical role of either a housewife who endorses domestic products or enhances the sexual appeal of the advertisements. The paper methodologically looks at parameters such as her role, age, setting and endorsement etc. in the context of television viewership and magazine publication and circulation.

A critical review of films which cast the LGBT community has been attempted by Pushpinder Kaur (2017) who elaborates in her article on the approach to representation of homosexuality in Indian cinema. 
Fatoon Ahmad Othman (2018) published a research article which critically analysed the medium of You Tube as an important tool for learning and engagement in institutions which offer higher education. It uses SWOT analyses to discern its positive and negative aspects and its impact as an educational tool. Burhanettin Keskin (2018) in his article on You Tube videos elaborates about the dimension of public education through content analyses; where its perception is segregated as positive, negative or neutral. This research is a qualitative enquiry which refers to a theoretical framework given by Professor Louis Gianetti wherein he introduced the genre cycle theory which has been referred to for comprehending the subject of taboos in short films. The current body of research is done with reference to advertisements and films and does not look at the medium of short films, specifically with reference to the subject of taboos. The existing matter on short films is in the form of short online essays which analyses either a particular film or general popularity trends in viewership. There is a brief description of the films with no critical investigation of its aspects such as setting, cast and appeal. The current research aims at identifying the style adopted for dissemination of ideas through selective short films on taboo subjects and their appeal and aesthetics.

India is a country with diverse cultures and there are numerous social taboos which are practiced since ages. The current research analyses three such popularly practiced taboos; which are gender biases, homosexuality and menstruation for a holistic understanding towards the methodology adopted in depicting them. Short films that have been published on You Tube have been considered with their date of publishing and channel as an important parameter for investigating into the phenomenon for the current decade. A minimum sample of ten case studies for each of the three taboos have been viewed and evaluated in the context of relevant theoretical framework.

\section{THE TABOO OF GENDER BIAS}

Anurag Kashyap's 'That Day after every day' (2013) is set in the context of everyday life situation in a city, where three working women are harassed by a group of men on way. With no support from family and overlooking as an initial reaction, the discomfort is gradually transformed into anger, provoking them to fight for their freedom. This realistic film is directed by a commercially successful director and has a well-known cast comprising of Radhika Apte, Sandhya Mridul etc. It aims to highlight the issue of late working hours and security of women, adopting a combination of emotional and pragmatic approach for establishing gender equality.

Mamas' Boy (2016) starring popular actresses Neena Gupta and Aditi Rao Hydari is an entertaining take on sexism, humorously represented in the historical garb of the epic of Mahabharata. Typicality of middle class youth attitude is depicted where the visual appeal is enhanced with a curious amalgamation of contemporary and historical props. The film subtly mocks at the docile nature of women in past and their new age avataar which is unapologetic of its sexuality, hence breaking the gender stereotype. Popular actor Manoj Bajpayee and Pooja Chopra starrer Ouch (2016) represents

woman as a more pragmatic gender as compared to the man. The film shot in a luxurious setting, depicts the traumatised situation of a man when his woman decides to quit their extra marital relationship. It is presumed that in such a situation, women do not take lead and make decisions and are deceived by men. Though the plot generates empathy in the viewers for the lead character, it aims to change the sensibility that one associates with Indian women. The Virgins (2016) by humaramovie is a simple story of a middle class couple on the verge of matrimony. The young girl and boy are uncertain yet want to break the age old rule of being virgin before marriage. The film also highlights the gender biases associated with female gender as compared to the males, who are instead supported by friends. The visual approach is believable and encourages a more open attitude towards the tabooed subject. Interestingly, brands such as Titan also delve into the bold wave of social change through short films such as Break the Bias (2016). This very short story is set in a conference room of an office with mostly male colleagues. The conversation is about Kiran who is mockingly appreciated for the dedicated work and extra efforts after office hours. The visual depicts the presumption associated with the name and is shattered when a male name Kiran walks into the room. The film subtly makes a satire on the conventional mind set associated with working women.

The year 2017 witnessed a sudden upsurge in the number of films and celebrities experimenting with taboo themes. The emotion of anger and frustration finds a believable expression in a short film titled Juice (2017) by Neeraj Ghaywan. Shefali Shah plays the role of an archetypal housewife in the background of indifferent family and friends who visit for a get together. Fulfilling continuous demands in hot weather, she is aggravated to the extent of giving up her expected role of serving them and sits down to enjoy her glass of juice with cool air. The crisp storyline and brilliant screenplay is what makes it relatable to every lower and middle class housewife in India. The film aims to sensitize public on gender roles and cuts down on unnecessary display of emotion to enforce a more humane approach to women. Naked (2017) is a short film which gained much popularity because of its title. Starring popular actress Kalki Koechlin who plays the role of a successful movie star and Ritabhari who interviews her, the film is a pragmatic dialogue between two females on taboos associated with nudity and creative freedom. The plot begins with Ritabhari uncomfortably discussing issues related to nakedness and publicity in the context of an actress's profession. The calm attitude and clarity of thought displayed by Kalki's character aims to make the audiences realize that the discomfort and body shaming begins with women.

Khaney mein kya hai (2017) is another metaphorical short film on the recipe of sexual desires, asserted through a light hearted conversation between a stereotypical mother and her daughter who is recently married. Shot in a simple kitchen setting, it explores the notion of hesitation of expression and submission to a man's desire as a past concept. The young daughter who embodies sexual confidence convinces her 
mother that expression of female desires is what characterizes the young women today. With its next door characters, the narrative encourages a more open conversational platform on sexuality and aims to change the established notions about the female gender. The Good Girl (2017) is an emotional drama on the taboo of premarital sex and parental attitude in India. A washroom setting defines the private enclosure for a dialogue between a mother and a daughter, when she discovers her daughter's probability on pregnancy. Television actress Gurdeep Kohli brilliantly exemplifies a typical mother who is initially annoyed and angered but decides to stand by her daughter in the time of distress. The film aims to sensitize parents on the acceptance of sexual needs by children and is a propagation of changing attitudes, much needed in India.

Going Dutch (2017) starring popular actress Gul Panag is a short film on gender biases associated with matrimony in India. She plays the character of a woman who successfully breaks the stereotype in the context of a matrimonial meeting through sharing her unconventional choices in life usually associated with the male gender. Represented as a confident woman who independently makes her own decisions, the film is a rational take on taboos associated with gender roles and matrimony. Another film with a commercially successful star is White Shirt (2017) with Kunal Kapoor and Kritika Kamra. The narrative is simple where the woman embodies a strong character that moves ahead of her relationship infidelity and though emotional about it, she is decisively logical. The film aims to encourage assertiveness and progressive outlook and breaks the taboo of emotionally weak women.

One of the most iconic short films of the year was perhaps Churri (2017) which starred commercially successful actors in a bold narrative on acceptance of an extra marital relation. Tisca Chopra in the role of a middleclass wife is aware of the infidelity of her husband played by Anurag Kashyap. She decides to visit Surveen Chawla who plays the role of 'the other woman' to manage the weekly visits of her husband to synchronize her own family routine. Sharp and blatant dialogues create the image of a new age women who is shrewd and unapologetic. With its believable approach, the film aims to usher a social change in attitude associated with quiet suffering and resignation to situations. Girliyapa's channel released a short film on Women's Day, titled Mom I'm not a Virgin (2017). It is a spontaneous take on a mother discovering her daughter's sexual relationship and her consequent reaction for sex as a taboo in Indian society. Set in a middle class household with local cast, the film explores through open discussion the efforts made by children to change their parent's attitude towards the taboo of premarital sex on rational grounds.

Nariyal ke laddoo (2018) by WWI films is a realistic representation of the biases associated with gender roles, enacted by local actors. The film depicts a wife who is working while her husband is frustrated due to unemployment. The emotion of anger dominates with the hesitation that one associates with typical middleclass households in India. The title justifies the stress of expecting the arrival of mother in law who is unaware of this situation. Virginity Test (2018) by Wynk Music uk is a factual enactment by local actors on the tabooed theme associated

with Indian women. The drama of a court room revolves around the victim and a woman lawyer who logically proves how the society demands only women to give their virginity test. The narrative revolves around a man who is conscious of getting married to a virgin and his disapproval to accept his newly wed bride for scientifically proved reasons. The film through its simple approach creates awareness and aims to break the traditional notions associated with women. The Choice (2018) by Blush films is another believable conversation between a mother and daughter about making a choice in life about pregnancy. It is the positivity and light hearted approach which encourages parents to change their mind set towards their children.

Chupchap (2019) is an emotionally moving narrative of a middle class mother who is silenced by her husband on the issue of rape. The narrative is believable with a mother who is constantly concerned for her teenage daughters' security. However, the trauma of her missing daughter ends in the tragedy of her own rape, which goes unreported. The film despite its local cast brings forth the taboo associated with the crime and sensitizes people on the lack of support system offered by family.

The taboo of homosexuality-In the current decade, there has been a more frequent attempt to adopt the theme of homosexuality in short films. With its growing demand and ultimate legalization in September 2018, various aspects that encompass the life of the LGBT community have been represented more earnestly in short films. The You Tube channel of Six Sigma Films dedicated itself to the cause and released many films in the current decade.

Birthday (2013) is a short film with average city life context and local cast, which explores the misunderstanding of homosexual relations between two men. The film sympathetically represents the nostalgia and frustration of being rejected by a person and aims to sensitize the general public on their attitude towards homosexuals.

Them (2014) is a very short film with no dialogues but only music which visually focuses on the concept of matrimonial meeting. It introduces a middle class boy and a girl conversing and preparing for an arranged meeting with their parents. Surprisingly, as we approach the end, we are made to realize that that the meeting is of their same sex partners with their proud and happy parents; who have readily accepted the sexual status of their children. Released at a time when homosexuality was not legalized and its local cast, it aimed at encouraging a positive and unbiased support from the community against this taboo.

Relations (2017) is an emotional take on the life and complexity of a gay film director who explores his emotions through multiple relations. The content of the film does not have a very broad public perspective but is a subjective insight into the life of a homosexual; who is confused, has intimate moments and a breakup like any other normal love relation would. With its local cast, the film subtly aims at sensitizing the people to change their notions about treating the community in a normal manner. 
The Chair (2017) is a short film based on a unique theme of personality transformation of a man who is gay. The storyline begins with a woman who is a makeup artist and she helps a man by giving him a lift; only to discover his frustration with the world. They visit her studio wherein she unconditionally helps him to transform using her makeup skills. The film aims to depict the emotional comfort that a person experiences on acceptance by self and others. The dialogues are limited and the visual narration leaves a powerful impact on the viewers.

In the Closet (2017) by Slug Line Films is a mediocre storyline set in a middle class household. The narrative is about a young girl's realization of her homosexuality and her family's gradual but unconditional acceptance of the same. Though the screenplay is average, the message to the audience is aimed at encouraging open discussion on the subject and recognition of it as normal.

Affinity of Touch (2018) is a short film by The Snapshot Entertainment which is based on a young boy exploring his sexual orientation through friendship and concern of his family. The main protagonist is a simple boy, who has loving feelings for his best friend and is not interested in women. His concerned elder bother doubting this relationship arranges for a prostitute to lure him who eventually helps him to discover his sexuality. The approach of the film is simple and straightforward and touches upon the theme of homosexuality at its budding stage.

Wajah (2018) is a half an hour long dramatization set in the beautiful state of Himachal. Two men discover each other's companionship through a similarity of stressed situation in life. They find friendship and a reason to support each other for progressing in life which eventually leads them into a loving relationship. With its average cast, the film targets to change notions about friendship and encourage a normal attitude towards the taboo.

The Surprise Date (2019) is an interesting narrative of a matrimonial meeting between two men arranged by their parents. The narrative is simple and pragmatic and ushers in a positivity which one could associate with in the coming time.

The taboo of Menstruation- Representation of the taboo of menstruation is majorly dealt with rationality and there has been a more frank approach to the subject in various social contexts.

A unique approach towards the subject was adopted by Csmsindia with their short film, released for women's day on 2017. It is a factual dialogue on premenstrual syndrome portrayed by a loving couple, aimed at creating awareness for the issue and encouraging better treatment for women. Tee Foundation's Pad Bank (2017) is a short film endorsed by popular actor Anushka Sharma. The narrative deals with a poor family consisting of a motherless girl and her father and the onset of periods. It highlights the issue of avoiding school and affordability of the basic sanitary pads. The film generates empathy in viewers and inspires to create a Pad Bank which can be economically viable for all. Alert condition: Red (2017) is one of the most popular short films on the subject. The plot is set in public space, where men make mockery of a young girl who is unaware of her menstruation. A man and a woman, both strangers offer help and guidance to the young girl in the moment of distress. The film with its rational approach sensitizes the viewers on

dealing with similar situations and respecting women. Bharath Mata in new India (2017) also released in the same year, adopts a humorous approach toward the seriousness of the issue in the context of governmental policies. The narrative depicts a woman in mythological attire embodying Indian mother, who visits a medicine store to discover how products related to menstruation are more expensive than other essentials. Released by Black Sheep films, it aims to ridicule the existing system and highlight the issue of economic affordability.

Six Sigma Films won many accolades for its film GaokorA Period House (2018), a short film deals which deals with the popular rural practice of early marriage and social discarding of women during her period days. The plot is set in a village wherein a young girl is exiled during menstruation, is raped and is blamed for the same. The film aims to create awareness of the prevailing ignorance on the subject, its frustrating practice in rural India and the insensitive approach towards women. Large Short films also released a profound short film titled 'Her First Time' (2018) which is based on the theme of a father dealing with menstruation. The plot depicts a working mother who thoughtfully prepares for her daughter's first period but is unavailable and hence guides her husband to deal with his daughter's situation. The film set in the background of an average household is believable and encourages men to comfortably share the responsibility with women. DRJ record studios' short film Periods (2018) represents a stereotypical middleclass family situation into which a girl gets married into. The main character displays anger for not being cared for during the difficult time of menstruation as she exhausts herself with daily chores. This trauma of insensitivity ends with a dream, leaving the audiences with an important message of being more considerate to a woman's need.

Another emblematic family situation is the reaction on first periods in the nine minute hilarious short film Mom, Dadi aur periods (2018). The storyline highlights a liberal grandmother played by popular actress Suhasini Mulay, who is shown as a more sensible character contrasting against the girl's mother who is superstitious and hesitant to talk of periods. The film produced by You Tube channel Girliyapa, takes a light hearted and entertaining approach towards the subject and emboldens the viewers to be more open minded. Mira Productions' five minute silent short film titled as Girls common secret (2018) is an emotional narrative with a strong social message. The plot depicts a generous rickshaw puller who helps a school girl by purchasing sanitary pads and dropping her home during her periods, unlike general public who mock at her situation. The simplicity of the theme and its visual approach aims to create cognizance on dealing with the issue. Period. End of sentence (2018) is an Oscar winning short film set in rural India. One such unique approach to the subject was adopted by Dasra and MH Alliance in their short film titled First Period: An MHM Story (2018), produced by popular actress Twinkle Khanna. The innovative aspect of a family dealing with onset of menstruation is through casting 
the male gender only. The film aimed to encourage open dialogue by the male community on the taboo of menstruation.

Six Sigma Films' The Best Gift (2019) is a short and silent spectacle of friendship. It is an emotional narrative of two friends in a village school setting, where gestures and emotions convey the discomfort and hesitation associated with periods. The girl runs to spend all her saving on purchasing a pack of sanitary pads, which justifies the title of the best gift.

Results: The results decode that towards the end of this decade the frequency of short films for taboo subjects has increased.

1. The prime cast of short films made earlier in this decade consisted of local actors or those who acted as secondary cast decade, the prime cast consisted of commercially successful celebrities; with film narratives that aim to bring a social change by depicting bold and unregretful women .

2. There is also an increase in the number of commercially successful directors who are opting for the format of short film for its low budget, quick accessibility and mass impact.

3. The positive impact of these short films is evident through its impressive viewership count and the number of likes that outnumber dislikes in all cases.

4. The visual approach for dissemination of ideas is an amalgamation of emotional as well as pragmatic attitude. In most films, the narrative is set in the backdrop of a middle class lifestyle with a rare few in rural setup.

5 . The theme of gender bias with its various nuances is more widely explored by directors as compared to other forbids. The taboo of homosexuality is not favoured by celebrities and the thematic experimentation of the films is evident. It is imperative to note that the subject of short films on gays forms a majority on the subject and there is a scarce number on lesbians. With regard to the taboo of menstruation, celebrity as prime cast appears rarely towards the end of the decade and there is a more open liberal approach towards educating the masses, especially the male gender.

\section{DISCUSSION}

The medium of short films has gradually grown in popularity over the past two decades. Not much research is available on the same as commercial cinema, advertisements or other broadcasting mediums are preferred mediums for study. To enumerate one such issue with short films is its actual release date and its online publishing. The discrepancy affects our understanding of its impact caused over a specific period of time. For comprehending a forbid such as gender bias, the number of people who like or dislike cannot be identified on the basis of gender; and the lack of this information affects impartial decoding of the results. The search engines utilized for finding short films do not comprehensively provide categorized information on specific issues. Most results are based on trending films, newly launched or awarded films.

Launch of new platforms such as Hotstar, Amazon Prime, Zee 5 etc. have also impacted viewership in multifarious ways. Hence, the impact of short films released on any in commercial cinema; whereas towards the end of the

specific channel cannot be understood holistically and would require further research.

Declaration of interests

I hereby declare that this research is an original body of work and is not under consideration for publication elsewhere. I have no known competing financial interests or personal relationships that could have appeared to influence the work reported in this paper.

\section{REFERENCES}

1. Agarwal, Ruchi. Changing Role of Women in Indian Cinema, Silpakorn Univeristy Journal of Social Sciences, Humanities and Arts. Vol 14 Issue 2,2014, pp 145-160.

2. Chaudhuri, Maitrayee. Fernandes, Leela ed. Gender Media and Popular Culture in a Global India, Routledge Handbook of Gender in South Asia. Pp 145-159.

3. Kaundal, Manju \& Thakur, Bhopesh. A Dialogue on Menstrual Taboo. Indian Journal of Community Health. Vol 26. 2014, pp 192-195.

4. Kaur, Pushpinder. Gender, Sexuality and (Be) longing: The Representation of Queer (LGBT) in Hindi Cinema. Amity Journal of Media and Communication studies: Vol 7 No. 1, 2017 , pp 22-30.

5. Keskin, Burhanettin. What do You Tube videos say about Public Education? Sage Publication: 2018, pp 1-5.

6. Othman, Ftoon Ahmad. You Tube as Engagement and Learning Tool in Higher Education Society. Journal of Fundamental and Applied Sciences: Vol 10, No. 4S, 2018, pp 137-142.

7. Ranjana, Mahajan Sagar Bahskar. Recent Gender Based Categorized Comparisons of Bollywood Movies Through Radar Plots. International Journal of Innovative Technology and Research, Vol 4 Issue 2, 2016, pp 2844-2851.

8. Roy, Subhas Singha. Portrayal of Women in Indian Media in the Era of Neo Liberal Economy. Global Media Journal, Indian Edition: Vol 3 No.1, 2012. pp 1-5.

9. Titzmann, Frtizi-Marie. Contesting the Norm? Live in Relationships in Indian Media Discourses. South Asia Multidisciplinary Academic Journal: Vol 16, 2017, pp 1-22.

10. Verma,Tarishi. Finger on your lips: Indian Sanitary Napkin Advertisements and the Culture of Silence. Sub/Versions Journal of Emerging Research in Media and Culture Studies: Vol 3, Issue, 2015, pp 158-183.

\section{Websites:}

1. http://asu.thehoot.org/research/special-reports/why-short-films-ha ve-begun-to-make-it-big-10217

2. https://www.hindustantimes.com/tv/juice-review-neeraj-ghaywanputs-everyday-misogyny-in-sharp-focus-watch-video/story-ROZ BoGanUUm4CxiOTcg8nL.html

3. https://www.statista.com/statistics/578364/countries-with-most-in stagram-users/

4. https://www.thenewsminute.com/lives/816 https://www.youtube.com/watch?v=DcvnPDqZVH0 https://www.youtube.com/watch?v=TkWllNbl7iA

5. https://mediaindia.eu/cinema/short-films-growing-in-stature-in-in dia/

https://www.freepressjournal.in/featured-blog/short-films-are-m aking-headway-into-the-indian-psyche/974659

6. https://timesofindia.indiatimes.com/business/india-business/Bran ds-flirt-with-taboo-topics-in-TV-ads/articleshow/25337309.cms

7. http://www.adageindia.in/advertising/5-ads-that-defy-social-taboo s-in-india/articleshow/47632481.cms

8. https://www.exchange4media.com/advertising-news/rewind-2016 advertising-campaigns-that-broke-social-stereotypes-67230.htm

9. https://scroll.in/article/829820/indian-brands-are-discovering-fem inism-and-gay-rights-not-the-least-because-they-sell

10. https://mediaindia.eu/cinema/bollywood-explores-indian-social-ta boos/ 
11. https://www.moneycontrol.com/news/trends/entertainment/badha ai-ho-how-bollywoods-fresh-approach-towards-tackling-social-t aboos-is-earnings-big-bucks-3075811.html

12. https://www.freepressjournal.in/entertainment/prem-rog-to-lust-st ories-when-indian-cinema-stepped-into-taboo-land/1307677

13. https://www.freepressjournal.in/featured-blog/short-films-are-mak ing-headway-into-the-indian-psyche/974659

14. https://www.thehindu.com/life-and-style/changing-milieu-of-adve rtising-of-sanitary-napkins/article23614529.ece

15. https://www.scoopwhoop.com/inothernews/indian-ads-celebratin g-modern-women/\#.ignuwdk23 